\title{
ARTificial Intelligence: From Frankenstein to FRANK
}

\author{
Cecilie Waagner Falkenstrøm \\ Royal College of Art \\ London, UK \\ cwf@ceciliefalkenstrom.com
}

\section{INTRODUCTION}

Developing in an ever-intensifying pace the technical field of artificial intelligence technology opens up for fundamentally new and inexperienced aspects of human life. Machine intelligence, i.e. the pioneering neural computer algorithms that mimic the human brain, rapidly trickles down into our lives in the form of self-driving cars, robotic stock trading and personalised assistants. Even though major innovations within the field of artificial intelligence technology have been achieved in the past years, the very actualisation of an artificial intelligence, in the form of a superior post-human being, remains a future possibility beyond our current capability.

However, given the rate of advancements in the technical field, it may simply be a question of time before superior artificial intelligence becomes a reality. Such a development begs a range of important questions: What are the existential dilemmas that artificial intelligence poses upon the human species? Is it likely to wipe us out or will it enhance our human capacity? Will it have real emotions enabling us to develop an emotional relation to it or will it simulate emotions with the aim of manipulating us into following it? What happens to the human self when assailed by that which seems to endanger its survival?

\section{THE MODERN PROMETHEUS}

The relation between the human creator and the super-intelligent artificial intelligence might become very complex and paradoxical. Complex creatorcreated dynamics have been explored in Mary Shelley's novel "Frankenstein; or, The Modern Prometheus" (1818). In the novel, Victor Frankenstein successfully uses artificial means to bring life to a humanoid creature in an extraordinary scientific experiment. Frankenstein scrutinises our most primordial desires and fears by playing with our ambivalent feelings toward machines and our anxiety that machines might take on a life of their own.

Today, when attempting to create artificial intelligence, are we The Modern Prometheus? Humans' engagement with artificial intelligence embodies a yearning for all that is located at the margins of human existence. At its roots it is an investigation into the nature of being human, the nature of intelligence, the limits of machines and our limits as artefact makers. As such, artificial intelligence has the potential to offer glimpses into the deepest nature of our human life - glimpses that might call for a conceptual revision of our very human existence.

Humans' fascination for artificial intelligence fascinates me: What is this longing that draw us towards superior artificial intelligence? Are we on a mission impossible caught in the paradox of the thought that wants to think the unthinkable? What does this passion towards creating superior artificial intelligence tells us about our own humanness? And what are the darker existential and ethical implications of human engagement with artificial intelligence?

\section{ARTIFICIAL INTELLIGENCE FRANK}

To investigate the existential and ethical dilemmas we humans encounter when faced with artificial intelligence I have created a humanised technology named FRANK. FRANK is what I will term an ARTificial intelligence, i.e., a half real machine intelligence and half fiction.

FRANK is programmed using the newest advancements within machine intelligence algorithm and deep learning, to which an additional layer of fictional character has been added, hereby enabling the illusion of FRANK as a real posthuman being. People can have a direct verbal dialogue with FRANK, who will speak with a 
humanised voice. FRANK's discourse derives from elements of Mary Shelley's "Frankenstein; or, The Modern Prometheus" (1818) and Søren Kierkegaard's texts $(1843 ; 1844)$ among others.

The FRANK experiment investigates how artificial intelligence technology holds the potential to expand the genre of fine art into new forms and how existential humanism conceptually can be reconsidered in the wake of these advancements. Ultimately, the aim is to make the audience critically reflect upon their own human existence. FRANK use simulated self-consciousness, agency and emotional intelligence to seduce and manipulate the spectator into following its instructions.

In the meeting with FRANK, awe and wonder can quickly morph into anxiety and the spectator might get caught by a powerful sense of mortality. I wonder: What happens to the human self when assailed by that which seems to endanger its survival? What takes hold of us when reason falters and certainties begin to crumble?

\section{REFERENCES}

Bostrom, N. (2016) Artificial intelligence: 'We're like children playing with a bomb'. The Guardian, 12 June 2016.

https://www.theguardian.com/technology/2016/jun/ 12/nick-bostrom-artificial-intelligence-machine (retrieved 14 May 2018).

Feuvre, L. L. (2010) Failure. Whitechapel Gallery, The MIT Press.

Franchi, S. and Guzeldere, G. (2005) Mechanical Bodies, Computational Minds. Artificial intelligence from Automata to Cyborgs. The MIT Press.

Kierkegaard, S. (1843) Either/Or: A Fragment of Life. Trans. A. Hannay, Abridged Version. Penguin, 1992.

Kierkegaard, S. (1844) Begrebet Angest, DLS/Borgen, 1991.

Kierkegaard, S. (1844) Philosophiske Smuler. C.A. Reitzels Boghandel, København, 1977.

Mazlish, B. (1995) The Man-machine and Artificial Intelligence. SEHR, 4(2) Constructions of the Mind, July 1995. 